\title{
SURTIDOR DE FUENTE PROCEDENTE DE LA VIVIENDA DE C. IVLIVS SILVA- NVS EN SEGOBRIGA (SAELICES, CUENCA, CONVENTUS CARTHAGINENSIS)
}

\author{
ROSARIO CEBRIÁN FERNÁNDEZ \\ Parque Arqueológico de Segobriga
}

\begin{abstract}
En la campaña del año 1998 en Segobriga se excavó la vivienda del procurator $C$. lulius Silvanus junto a las termas monumentales, construidas en época severiana. En una de las estancias se localizó un santuario de tipo oriental, sobre restos de otro indigena, dedicado al culto a Zeus Theos Megistos. El surtidor de fuente con representación del dios Océano que aquí presentamos formó parte de la decoración ornamental de esta estancia.

During the 1998 excavations in Segobriga, the house of the procurator C. lulius Silvanus, constructed during the Severian period close to the Monumental Baths was excavated. An oriental-style sanctuary dedicated to the cult of Zeus Theos Megistos was found in one of the rooms, built on the remains of an earlier indigenous sanctuary. The fountain jet shown here represents the god Oceanus and formed part of the ornamental decoration in this room.
\end{abstract}

A finales del siglo II d.C., C. Iulius Silvanus se construyó una casa en el solar situado en una de las terrazas superiores de la antigua ciudad de Segobriga, al noroeste de las termas monumentales y separada de ellas por una calle. Este personaje, identificado con $C$. lulius Silvanus Melanio, procurator provinciae Hispaniae citerioris, de origen griego, llegó a Segobriga para asumir el control de las explotaciones mineras dedicadas a la extracción del lapis specularis entre los años 198 y 211 d.C. (Abascal y Alföldy, 1998, 157-168).

En 1998, se iniciaron los trabajos arqueológicos en la vivienda de Silvanus localizándose tres estancias. En la denominada estancia $1 \mathrm{se}$ construyó un templo dedicado al culto a Zeus, según se desprende de la lectura de una inscripción griega hallada a escasos metros de esta estancia y de la presencia de una columna votiva de mármol blanco insertada en un bloque de piedra caliza y una basa de columna poligonal que se utilizó como mesa de altar. La estancia 2 presentaba un mosaico pavimental (Abascal y Cebrián, 1999, 299-301), decorado con un panel circular de triángulos blancos y negros, y sus paredes estuvieron ricamente decoradas con pintura mural (Cebrián y Fernández, 2004). La tercera habitación contó con un banco corrido, adosado a uno de los muros de esta estancia.

La excavación de esta vivienda continuó en la campaña de 1999 con la exhumación de dos nuevas habitaciones, situadas al norte de las tres anteriores. Los trabajos arqueológicos en esta domus no han concluido ni tampoco el estudio completo de la vivienda y de sus etapas de ocupación. A pesar de ello, en este trabajo damos a conocer un surtidor de fuente marmóreo asociado al sistema de cisternas documentado en la estancia 1 de la vivienda de Silvanus.

\section{1.- LA ESTANCIA 1 DE LA VIVIENDA DE SILVANUS}

La estancia, de planta rectangular, presenta unas dimensiones de 7,05 $\mathrm{m}$ de largo y $6,48 \mathrm{~m}$ de anchura. En el ángulo suroccidental de la habitación se documentó un muro (UE 1753), formado por piedras de mediano tamaño con todas sus caras trabajadas, que se apoya directamente sobre la roca y describe una $L$, que cerró un pequeño recinto en el interior de la habitación al adosarse a uno de sus muros de cierre. En el interior se encontraron tres 


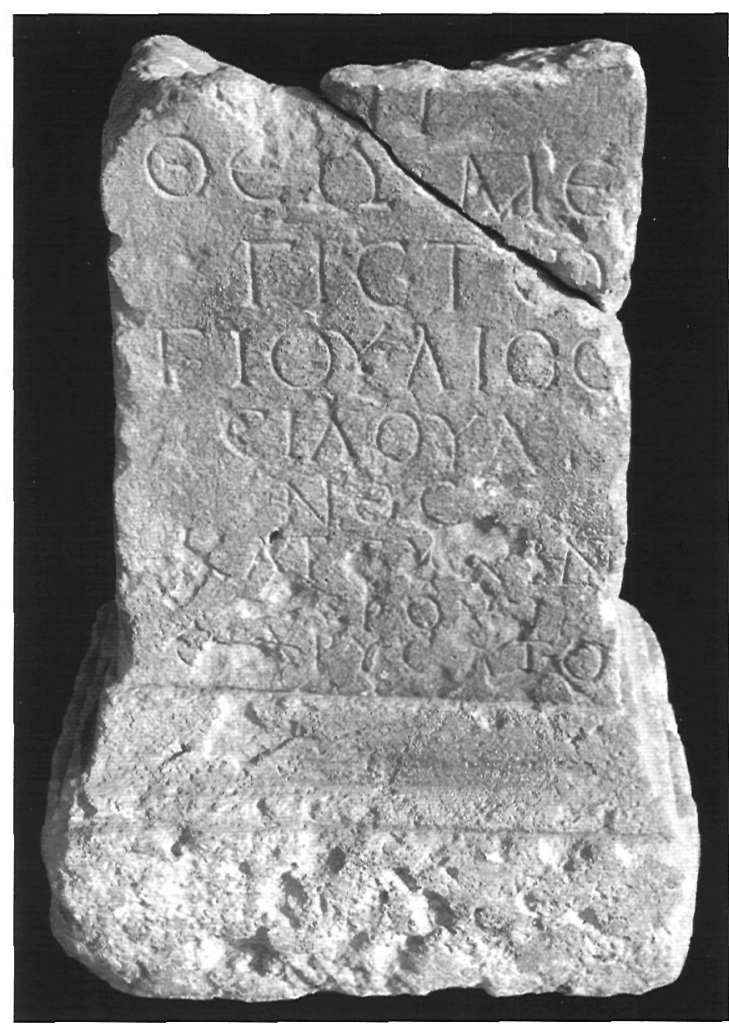

Figura 1: Altar dedicado a Zeus Megistos en Segobriga.

antefijas (Abascal, Cebrián y Cano, 2000, $n^{\circ}$ 28 al 30$)$.

Por encima de este muro se localizó un pavimento de mortero de cal (UE 1724) sobre el que se encontró caído un fuste y basa de columna de mármol, tallado en una sola pieza, la cual se colocó sobre un soporte de piedra caliza de sección cuadrangular. Junto a estos dos elementos, apareció un fuste de columna poligonal cuya cara superior se correspondía con la inferior de la basa de la columna, que pudo emplearse como mesa de altar. El relleno que cubría estos elementos presentaba gran cantidad de fragmentos de pintura mural, que formaron parte de la decoración de las paredes de esta estancia (UE 1725) y un nivel de adobe procedente del alzado de los muros (UE 1722). Ambos rellenos estaban cubiertos por un nivel de color amarillento (UE 1720), que hemos relacionado con la disgregación de la argamasa de los muros de la estancia y en el que apareció el surtidor de fuente marmóreo que presentamos en este trabajo.

Probablemente, este pequeño recinto documentado en la estancia corresponde al altar dedicado a Zeus, rematado por un tejado a doble vertiente donde se colocaron las antefijas localizadas en la excavación de esta zona (Fig. 1).
La estancia 1 presenta en su lado meridional una cisterna (UE 1031) que abasteció de agua a la vivienda y que se construyó entre el muro de cierre de la calle noroccidental de las termas monumentales y el muro meridional de la estancia. Ambos muros cimentaban directamente sobre la roca, lo que permitió soportar la presión de agua contenida en la cisterna. La balsa, construida en opus caementicium, tiene planta rectangular, de $8,18 \mathrm{~m}$ de longitud y $1,84 \mathrm{~m}$ de anchura. Al interior se impermeabilizaron los paramentos con una capa de opus signinum, de $1 \mathrm{~cm}$ de espesor y sus paredes conservan los característicos boceles hidráulicos en la unión con el suelo. La cisterna se abre por su lado norte hacia el interior de la estancia 1, describiendo una $\mathrm{U}$ de $2,02 \times 1,30 \mathrm{~m}$, donde creemos pudo situarse la estructura de la fuente, de la que formaría parte el surtidor documentado en la habitación (Fig. 2).

Adosado al muro de cierre de la estancia 1 por su lado oriental se localizó otra balsa (UE 1734), de planta rectangular, orientada en dirección NE-SW y unas dimensiones exteriores de $9,30 \times 2,92 \mathrm{~m}$.

Nada sabemos de la cubierta de estas dos cisternas y del sistema que se empleó para el almacenamiento hídrico, aunque su construcción debe relacionarse con el abastecimiento de agua a la domus de Silvanus.

\section{2.- LA FUENTE DE LA ESTANCIA 1}

En el mundo romano, la aparición de fuentes en espacios privados se atestigua a

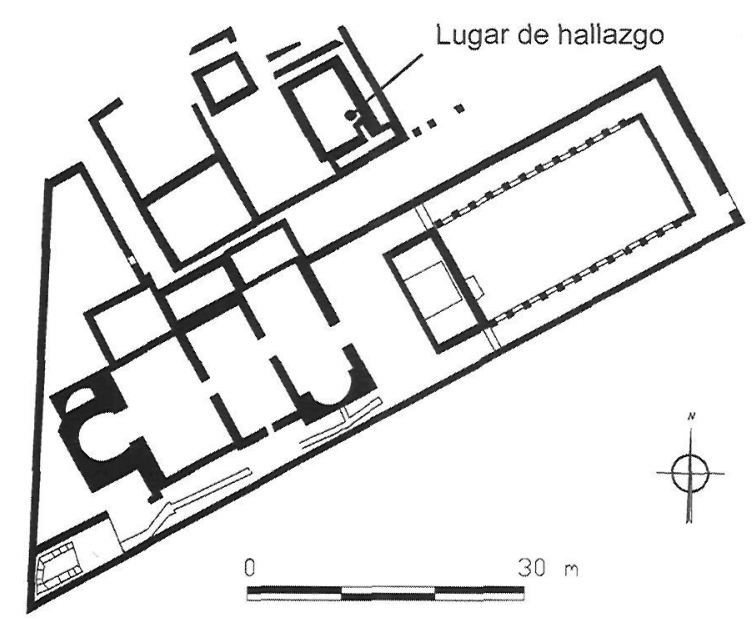

Figura 2: Planta de la vivienda de C. Iulius Silvanus y lugar de hallazgo del surtidor de fuente. 


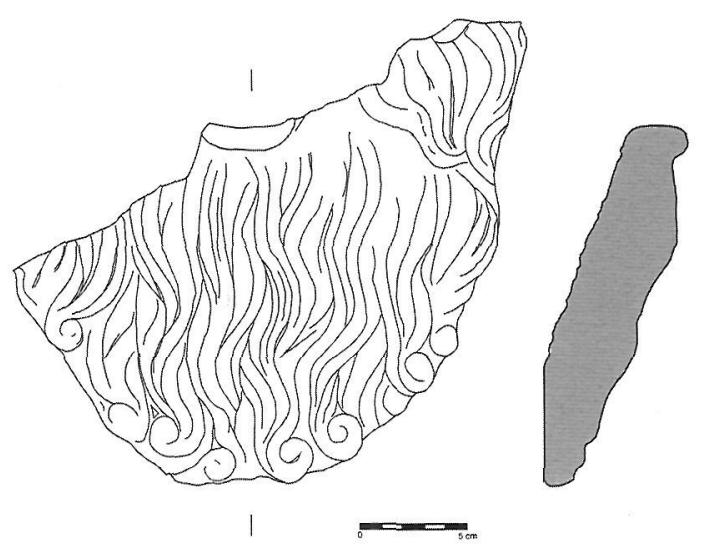

Figura 3: Dibujo y sección del surtidor de fuente.

partir del siglo II a.C. en las villae de la aristocracia italiana. A partir de época de Augusto, la construcción de acueductos para el abastecimiento en las ciudades comienza a generalizar el uso del agua corriente en ambientes domésticos (Dwyer, 1982, 113 ss.). Generalmente, las fuentes de uso particular se situaron en las habitaciones más representativas de la vivienda, tales como atrios, peristilos y comedores (Ventura, 1996, 116-117). El aspecto exterior de las fuentes documentadas en época romana es muy similar: el agua salía directamente de la pared, a través de una tubería, bajo la cual se situaba una cisterna. La fuente podía decorarse con elementos arquitectónicos, tales como pilastras y columnas. En los surtidores de las fuentes, realizados en piedra, mármol o bronce, se representaban distintos dioses tales como Mercurio, Océano, Venus, Fortuna y la imagen mitológica de Gorgona, aunque se continuó con la tradición helenística del león (Tölle-Kastenbein, 1990, 173).

Desconocemos la estructura de la fuente en la que se ubicó el surtidor ornamental que presentamos y carecemos de datos arqueológicos que permitan situar el lugar exacto donde se construyó. Parece probable, a juzgar por el lugar de hallazgo, que esta fuente se sitúo en la pared meridional de la estancia, detrás del altar dedicado a Zeus.

\section{1.- Descripción del surtidor de la fuente} (Fig. 3 y Fig. 4)

El surtidor de fuente documentado en la estancia 1 de la domus de Silvanus está realizado en mármol blanco de grano grueso ( $n^{\circ}$ inv. 98/1720/87). Las dimensiones conservadas de la pieza son $22 \mathrm{~cm}$ de longitud, $23,5 \mathrm{~cm}$ de anchura y $4 \mathrm{~cm}$ de grosor. Representa el rostro de una divinidad acuática, probablemente Océano, en posición frontal. Sólo conserva el labio inferior, parte del pelo y la barba. El pelo conservado permite considerar que éste se repartía a ambos lados de la cabeza en pequeños mechones, que caían sobre la barba, distribuida también en mechones que terminan en bucles. El agua de la fuente manaba de su boca. La cara posterior de la representación presenta su superficie alisada y un lado recto en su parte inferior, necesario para que el surtidor apoyara en la pared de la fuente.

La mitología griega otorgó al dios Océano la supremacía sobre los mares, las fuentes, los ríos y los lagos. La iconografía habitual de esta divinidad fluvial nos presenta a un personaje de densa barba rizada y con la cara en forma de disco, representando al "río universal", que rodeaba la tierra y daba origen a todos los cursos de agua (Hesiodo, Teogonia 133, 337 ss.).

\section{2.- El carácter sacro de la fuente}

La presencia de una fuente en la estancia convertida en un lugar de veneración a Zeus en la domus de Silvanus permite realizar algunas consideraciones acerca del posible carácter sagrado de la misma. El origen griego de este personaje debió influir en el valor simbólico de las fuentes como lugares de culto. En el mundo helenístico, en los manantiales se eri-

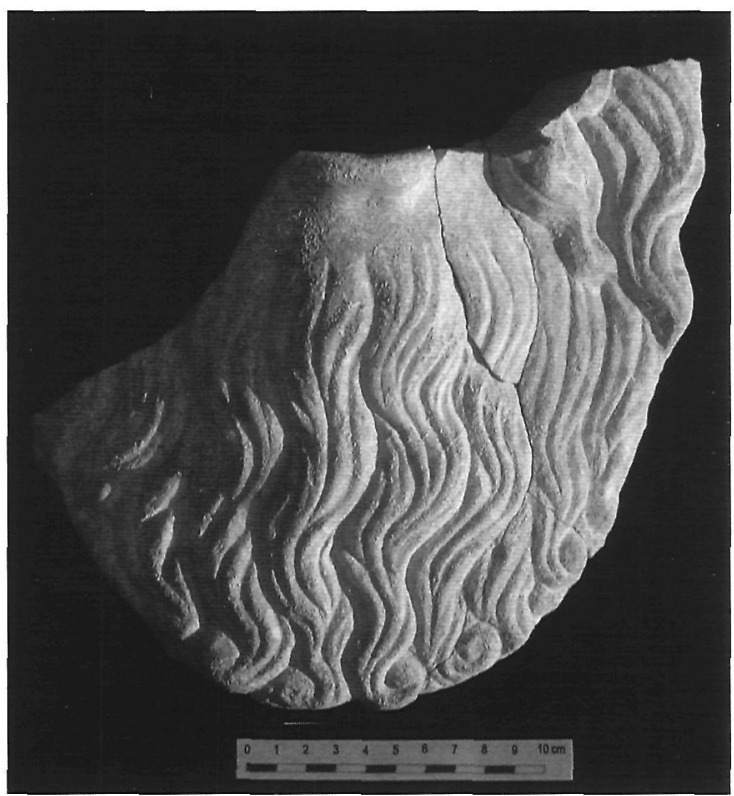

Figura 4: Surtidor de fuente hallado en Segobriga. 
gieron templos y en el interior de los santuarios se construyeron fuentes, en las que se realizaban ofrendas votivas (Glaser, 2000, 416420).

Zeus, la divinidad suprema del panteón supremo griego, representaba el poder sobre los fenómenos meteorológicos e incluso al agua mandada por él se le atribuian varias propiedades benéficas para la salud (Horacio, Epist. I 15, 14 ss.). Por ello, el agua era utilizada para prácticas cultuales en algunos recintos sacros, como por ejemplo en el templo de Zeus en Messenia (Tölle-Kastenbein, 1988, 187-188).

El significado del agua en ambientes sagrados del mundo griego y el propio origen del propietario de la vivienda pueden explicar la presencia de una fuente en una estancia convertida en santuario a finales del siglo II d.C. en Segobriga.

Rosario Cebrián Fernández Parque Arqueológico de Segóbriga 16430 Saelices segobriga@jccm.es

\section{BIBLIOGRAFÍA}

ABASCAL, J. M. y ALFÖLDY, G., 1998: "Zeus Theos Megistos en Segobriga", Archivo Español de Arqueologia, 71, 157-168.

ABASCAL, J. M. y CEBRIÁN, R., 1999: "Mosaico romano de Segobriga", Archivo Español de Arqueologia, 72, 299301.

ABASCAL, J. M., CEBRIÁN, R. y CANO, T., 2000: "Antefijas romanas de Segobriga (Hispania Citerior)", Anales de Prehistoria y Arqueologia, 16, 121-131.

CEBRIÁN, R. y FERNÁNDEZ, A., 2004: "Un techo pintado en la domus de G. Julius Siluanus en Segóbriga (Saelices, Cuenca. Conventus Carthaginensis", Plafonds et voutes à l'époque antique, Actes du VIIle. Colloque International de l'Association Internationale pour la Peinture Murale Antique, Budapest-Veszprém, 2002, Budapest.

DWYER, E., 1982: Pompeian domestic Sculpture. A Study of five pompeian Houses and their Contents, Roma.

GLASER, F., 2000: "Fountains and nymphaea", en Wilander, O. (ed.): Handbook of Ancient Water Technology, Brill.

TÖLLE-KASTENBEIN, R., 1990: Archeologia dell'acqua. La cultura idraulica nel mondo classico, Biblioteca di Archeologia, 20, Milán.

VENTURA, A., 1996: El abastecimiento de agua a la Córdoba romana. II. Acueductos, ciclo de distribución y urbanismo, Córdoba. 